\title{
ROTATING DETONATION: HISTORY, RESULTS, PROBLEMS
}

\author{
Anatoly A. Vasil'ev \\ Lavrentyev Institute of Hydrodynamics SB RAS, Prospekt Akademika Lavrent'yeva, 15, Novosibirsk, \\ Novosibirsk Oblast, 630090, Russia \\ Novosibirsk State University, 1, Pirogova str., Novosibirsk, 630090, Russia \\ gasdet@hydro.nsc.ru・ORCID 0000-0001-9231-0468
}

\begin{abstract}
Among of modern papers devoted to numerical modeling of rotated waves the greater part of papers are based on assumption that such wave propagates with velocity equals to the Chapman-Jouguet velocity of ideal detonation model with plane front. But the experimental velocities of rotated detonation waves, as a rule, are less (and even much less) the velocity of ideal Chapman-Jouguet detonation. Such regimes are named as low-velocity detonation or quasi-detonation and its characteristics are practically not investigated carefully. Moreover, similar to the spinning detonation, the strong connection of velocity of rotated transverse waves with the acoustic waves of reaction products was observed. So the new model with an allowance for the losses of impulse and energy must be used at numerical modeling of RDE and new experimental investigations of regimes with understated velocity must be carried out. In given paper some important aspects of rotated detonation waves and new experimental results are analyzed: the multifront system of rotated waves; correlation of rotation velocity of waves with acoustic characteristics of reaction products; streak-records trajectory of rotated waves on moving film; pressure and temperature profiles of rotating waves; velocity deficit and energy-release.
\end{abstract}

Keywords: spinning detonation, rotated detonation wave, self-sustained supersonic regimes and their nature, low-velocity detonation, "quasi-detonation", energy-release in reactive mixtures, instability of reaction zone, connection of DW instabilities with acoustic vibrations of reaction products, looses of impulse and energy.

\section{INTRODUCTION}

Starting from the initial period of investigations (about 140 years ago, for example [1-5]) the detonation wave (DW) was considered during long time as plane wave without any internal structure. It was great surprise when the unusual regimes of DW propagation in tube of round cross-section with spiral trajectory were observed in 1927 by Campbell and Woodhead [6]. Moreover, the long luminosity front (tail) with strong pulsation was observed in detonation products (Fig. 1a). This regime was named as the spinning DW and for a long time it considered as exotic detonation regime. About 20 years the efforts to find a connection among the unknown element of DW-front and long pulsation tail in detonation products were unsuccessful. Such connection was proposed by Prof. N. Manson, who proposed firstly in 1946 the acoustic theory of spinning detonation [7]. He assumed that the rotation of spinning detonation is connected with acoustic vibration of detonation products and found that the main acoustic disturbance (MAD) has the axial 
velocity $D_{\perp}^{S}=1,84 c$, where $c$ is the sound speed in detonation products, and 1.84 is the value of basic root of the Bessel function of the first order, which describes the radial component of velocity potential of a gas products for $2 \mathrm{D}$ acoustic equation. The time of one revolution of MAD is $t^{0}=\pi \cdot d / D_{\perp}^{S}(d$ is the tube diameter) and during this period the front of spinning DW shifts along the tube axis on distance $\lambda=D_{I I} \cdot t^{0} \cong \pi d$. The simultaneous propagation of MAD along the tube and its axial rotation ensures the spiral trajectory on inner smoked wall of tube with the trajectory slope to the tube axis $\operatorname{tg} \cdot \varphi_{S}=D_{\perp}^{S} / D_{I I}=1,84 \cdot c / D_{I I} \cong 1$, i.e. $\varphi_{S} \approx 45^{\circ}$, since $c / D_{I I} \cong 0,55, D$ is the longitudinal (along the tube axis) velocity of DW.
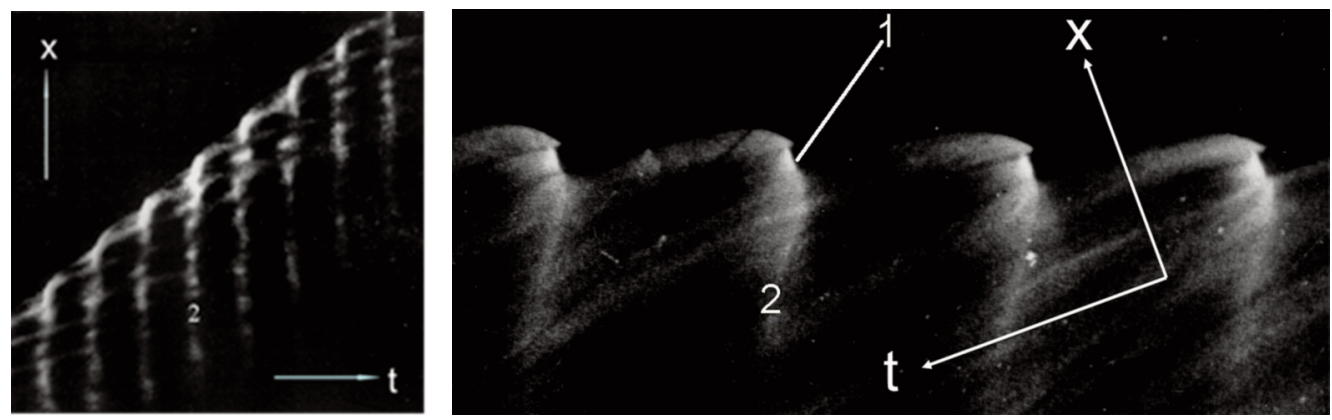

Fig. 1. Streak-record of propagation of the spinning detonation wave along the tube (a) and similar record of its structure (b) with the transverse wave (bright zone to be parallel to $\mathrm{x}$-axis -1 ) and the tail in products -2 . The axis of tube and streak photo-camera are parallel on left photo and are inclined on right photo (along X).

Later, the term of "transverse wave" (TW) was proposed by A.N. Voinov [8] (1950) for unknown element of spinning configuration of DW-front. The structure of spinning DW (as in modern point of view) was identified in 1957 firstly by Prof. B. Voitsekhovsky [9-11] (Fig. 1b). Spinning DW in round tube is the unique stationary process of wave

propagation with single transverse wave (TW, marked by symbol 1 on the right) on the DW-front, which axially rotates along internal surface of tube wall. This transverse wave is interfaced with the tail (symbol 2) of MAD in detonation products. Two photo of spinning DW on Fig. 1 illustrate the next: (a) streak-record of propagation along tube, registration across slit parallel to tube axis, oblique trajectory corresponds to detonation front, vertical lines (2) corresponds to acoustic tail in products; (b) streakrecord at special technique of registration of transverse waves, proposed by Prof. Voitsekhovsky [9-11].

The increased interest to use of a detonation process in various technological devices (the concept of detonation engine (DE)) was stipulated by Prof. Zeldovich Ya. B. [12] on the conclusion of the classical one-dimensional theory $[4,5]$ that the regime of the ideal Chapman-Jouguet detonation is characterized by minimum growth of an entropy $S_{\mathrm{D}}=$ min. The higher losses are inherent for combustion modes (laminar and turbulent) on a comparison with the C-J detonation mode, for example, at point of deflagration regime with maximal velocity $\left.S_{\mathrm{DF}}=\max \right)$.

The idea to burn mixture in detonation mode appears many years ago. In latest years many investigators from different countries are connected with problem of pulse detonation engine (PDE), when DW as cyclical process propagates along the tube. Prof. B. Voitsekhovsky was the first who proposed to burn the mixture in detonation mode with the help of rotating waves, likely transverse wave of spinning configuration. Two scheme were investigated more carefully for stabilization of rotating wave, located in some plane: a) components injection in radial direction (from centre to outside or from outside to center); b) the mixture components can be injected along the axis. On Fig. 2 one can see the photo of B.V. Voitsekhovsky at the defence of the doctoral dissertation about rotated detonation in Novosibirsk in 1961. 


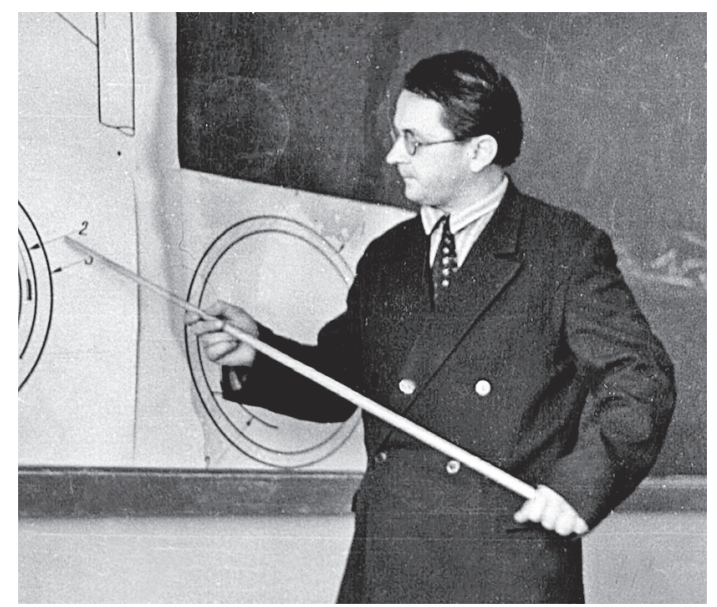

Fig. 2. Prof. Bogdan V. Voitsekhovsky.

The detonation mode of mixture burning with the help of stationary rotating detonation waves (RDW) was investigated effectively in Lavrentyev Institute up to now and the basic experimental results about RDW was published by Bykovsky and Zhdan [13-15]. At latest years this problem was investigated experimentally by many investigators in different countries - Russia, France, Japan, Poland, USA, China. Prof. Piotr Wolanski is the pioneer of investigations of rotating detonation in Poland and remarkable popularize of detonation engine in another countries [16-22]. During latest years the space structure of spinning and rotated DW was analyzed numerically in papers of many scientists (for example, [23-32]. Different aspects of PDE and RDE were analyzed also in papers of ICDERS ( http://www.icders.org/ ICDERS2019/index.html > 300 references, http://www.icders.org/ICDERS2017/index.html up to http://www.icders.org/ICDERS1999/index.html), in review of author [31], in latest review paper [33] with 379 references. In short paper it is impossible to nominate the whole of authors of papers, devoted to investigation of rotated DW. Moreover, only high quality papers with new fundamental results are deserving reference.

\section{HOW MANY STEADY REGIMES CAN BE OBSERVED IN ACTIVE MIXTURE?}

The classical one-dimensional theory of detonation is based on the laws of conservation of mass, momentum and energy, written in the wave front system for a constant-section fluid tube:

$$
\begin{aligned}
& \rho_{0} w_{0}=\rho w \\
& P_{0}+\rho_{0} w_{0}^{2}=P+\rho w^{2} \\
& H_{0}+w_{0}^{2} / 2=H+w^{2} / 2+Q
\end{aligned}
$$

Here $w_{0}$ and $w$ are the flow velocities of flowing into and out of the front, $V=1 / \rho$ is the specific volume of one mole per unit mass, the reciprocal of the mixture density, $P$ is the pressure, $H$ is the enthalpy, $Q$ is the specific energy release of the mixture. Within the framework of the ideal gas model with the equation $P=\rho R T=R T / V$ the enthalpy is expressed by the formula

$$
H=U+P V=\frac{\gamma}{\gamma-1} P V
$$


The first two equations of mass and momentum give the next ratio:

$\frac{P-P_{0}}{V-V_{0}}=-\rho_{0}^{2} w_{0}^{2}=$ const

which is the equation of a straight line in a plane $(P, V)$ - so called the Michelson-Rayleigh line (MRL). This last equation yields two useful relationships for velocities:

$$
w_{0}^{2}=V_{0}^{2} \frac{P-P_{0}}{V_{0}-V} \quad w^{2}=V^{2} \frac{P-P_{0}}{V_{0}-V} .
$$

Substitution these relations to the energy equation allows one to obtain several auxiliary formulas for entropy and internal energy:

$$
\begin{aligned}
& H-\left(H_{0}+Q\right)=\frac{1}{2}\left(w_{0}^{2}-w^{2}\right)=\frac{1}{2}\left(P-P_{0}\right)\left(V_{0}+V\right), \\
& U-\left(U_{0}+Q\right)=\frac{1}{2}\left(w_{0}^{2}-w^{2}\right)+P_{0} V_{0}-P V=\frac{1}{2}\left(P+P_{0}\right)\left(V_{0}-V\right),
\end{aligned}
$$

and also the equation $P=F(V, Q)$, called as the energy release adiabat (named also as the Hugoniot curve (HC)), which turns after transformations into the hyperbolic equation

$$
\left(\frac{P}{P_{0}}+\frac{\gamma-1}{\gamma+1}\right)\left(\frac{V}{V_{0}}-\frac{\gamma-1}{\gamma+1}\right)=1-\left(\frac{\gamma-1}{\gamma+1}\right)^{2}+2 \frac{\gamma-1}{\gamma+1} \frac{Q}{P_{0} V_{0}}
$$

At $Q=0$ the shock adiabat equation is obtained

$$
\left(\frac{P}{P_{0}}+\frac{\gamma-1}{\gamma+1}\right)\left(\frac{V}{V_{0}}-\frac{\gamma-1}{\gamma+1}\right)=1-\left(\frac{\gamma-1}{\gamma+1}\right)^{2}=\text { const }
$$

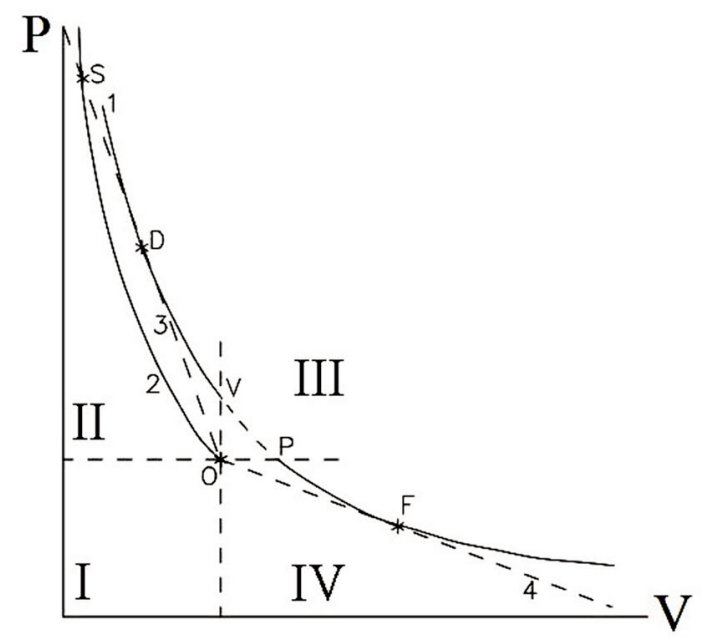

Fig. 3.Typical (P-V) diagram of combustible mixture and its products of chemical reaction. 
The well known $(P, V)$ - diagram of a combustible mixture and its products is presented on Fig. 3: $\mathrm{O}$ - point of initial state, 1 - the Hugoniot curve as the states of products of chemical reaction, 2 - the shock wave adiabat (SWA), 3 - the Michelson-Rayleigh lines (MRL) for steady detonation (point D) and steady deflagration (point F), S - the head state in chemical spike of DW, P and V - the states of products at reaction regimes $\mathrm{P}=$ const and $\mathrm{V}=$ const. Symbols I and III indicate the area of unphysical states (also dotted part VP on HC, where the sound speed must be negative - $\left.(\partial P / \partial \rho)_{S}=c^{2}<0\right)$; symbol II indicate detonation regimes, symbol IV - deflagration regimes.

At $Q=$ const the Hugoniot curve of energy release is a hyperbola, shifted relative to the point of the initial state $\mathrm{O}$, so the point $\mathrm{O}$ lies outside the hyperbola (Fig. 3). The shock adiabat is also a hyperbola, but it passes through the point $\mathrm{O}$. Many straight lines can be drawn from point $\mathrm{O}$ to the Hugoniot curve as a hyperbola. There are three cases for the relative position of the Hugoniot curve and the straight line: a) there is no intersection; b) there is an intersection at two points; c) the line and Hugoniot curve are touched. Stationary propagation modes correspond only to the points of tangency of the MichelsonRayleigh straight line and the Hugoniot curve - the combustion wave for the deflagration branch of the $\mathrm{HC}$ and the Chapman-Jouguet (C-J) detonation wave for the detonation branch of the HC. At $Q=$ const the next approximate formula are well known for velocity of detonation $D_{0 d} \approx \sqrt{2\left(\gamma^{2}-1\right) Q}$ and velocity of deflagration $-D_{0 d f} \approx 1 / \sqrt{2\left(\gamma^{2}-1\right) Q}$. From these formulas it is evident, that a decrease of $Q$ leads to decrease the detonation velocity and to increase the deflagration velocity. For the Hugoniot curve $Q=$ const it was determined that at the detonation point of contact, the change in entropy has the property of an extremum with a minimum of its change compared to the initial value, and at the point of contact with the deflagration branch, it has the property of an extreme with a maximum change in entropy.

Within the framework of a one-dimensional flow between shock hyperbola $Q=Q_{S W}=0$ and detonation hyperbola $Q=Q_{C-J}$ it is possible to draw many hyperbolas of partial energy release $Q=\alpha_{i} Q_{C-J}$ with $0<\alpha_{i}<1$ (Fig. 4). From the formal point of view, tangent lines can be drawn from the initial point $\mathrm{O}$ to each of these hyperbolas, which will determine the wave propagation modes for the case of partial release of the chemical energy of the mixture. This means that in addition to stationary detonation and deflagration (named as the Chapman-Jouguet regimes with full energy release of the combustible mixture) many modes with partial energy release can be existed formally. It is evident, that as the $\alpha_{i}$ - values and the angle of inclination of the M-R straight line decreases and changes, the detonation velocities will decrease from $D_{i}=D_{C-J}$ up to the sound speed of an initial mixture. At this the rates of deflagration combustion will increase.

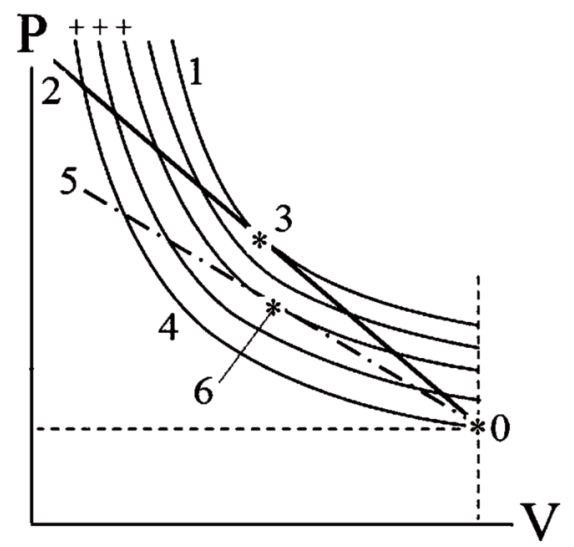

Fig. 4. Typical (P-V) diagram for regimes with partial energy release: 1 - the Hugoniot line for maximal $Q$ and corresponding MR line 2, 3 - the C-J state for $\mathrm{Q}=\max$, $5-\mathrm{MR}$ line for case of partial energy release with $\mathrm{Q}<\mathrm{Q}_{\max }$ and corresponding point of tangency $6,4-$ the shock adiabat, 0 - initial state of mixture, +- adiabat of partial energy release. 
The described situation with partial energy release could be realized by some ways: at change of removing energy from the system through the limiting walls due to heat removal, the death of active radicals on the walls and other various kinds of losses, at influence on mixture composition at separate injection of fuel and oxidizer and their mixed, at using of catalytic agents with the ability of clear control of chemical reactions and their energy release. These mechanisms make it possible to change the dynamics of the energy release of the mixture, but only with sufficiently strict limitations on the temporal characteristics of chemical reactions and the temporal characteristics of the used physical effects. The problem of effective control of the energy release of detonation and quasi-detonation waves is currently far from being solved, although this problem is extremely important for the developers of new propulsion systems operating not only in stationary combustion or detonation modes, but also in transient modes of rapid maneuvering.

\section{LOW-VELOCITY "QUASI-DETONATION"}

In the idealized one-dimensional model, the velocity of C-Jouguet DW at a fully completed reaction with $Q=$ const is the minimum velocity of stationary propagation of the $\mathrm{DW}$. The underestimated values of the spinning DW velocity are due to the extended zone of the chemical reaction and the increasing level of heat loss into the tube walls, which corresponds formally to a decrease of the DW energy release in comparison with the idealization of the classical model. The percentage of underestimation of the spinning DW velocity characterizes the maximum allowable level of energy loss, which still allows the wave propagation to be stationary. At large losses, the equilibrium is violated, and the stationary propagation regime goes over to an unsteady supersonic regime with decreasing amplitude. However, as it was established previously, the stationary regime of spin detonation is not limiting: there is a regime of "quasi-detonation", the speed of which is stationary and approximately equal to the sound speed in the products. A photographic streak-record of the luminosity of such a "quasi-detonation" process is shown in Fig. 5 - trajectory 1 with detonation velocity on the initial part of channel (up to indication arrow) and next transforming to "quasi-detonation" regime. One can see, that "quasi-detonation" wave propagates along channel with constant velocity without any disturbances.

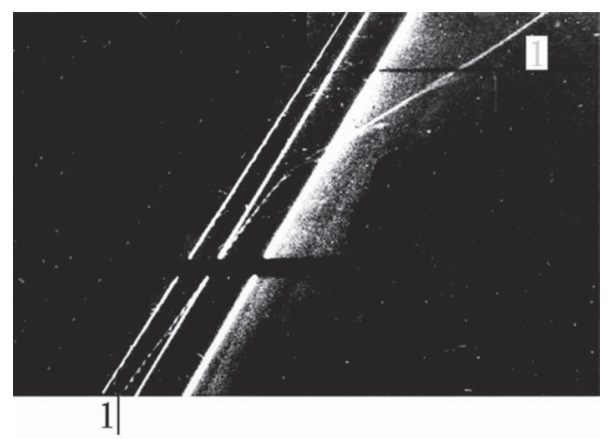

Fig. 5. The transformation of near-limiting detonation to low-velocity "quasi-detonation" (1-1 trajectory).

The "quasi detonation" modes are poorly investigated. Special attention should be paid to the experimental fact that often the rotating detonation mode also has a velocity significantly lower than the Chapman-Jouguet detonation velocity. The nature of such "quasi-detonation" regimes is still far from clear understanding and requires additional research. 


\section{LOW VELOCITY REGIMES OF ROTATING DW}

It must be mentioned especially that it seems easy to produce the rotated TWs propagated with the velocity of ideal C-J detonation $\mathrm{D}_{0}$. In the early works of B.V. Voitsekhovsky it was found that in a plane-radial devise with an annular combustion chamber, when a premixed mixture outflows from the center, a multi-headed regime of propagation of rotating detonation is realized with velocities that are noticeably underestimated in comparison with the velocity of an ideal Chapman-Jouguet DW. As a rule the velocity of rotated wave $\mathrm{D}$ is less $\mathrm{D}_{0}$ and $\mathrm{D}$-value is closed to value of sound speed of detonation products c (usually). The reason for this decrease remained unclear, since references to poor-quality mixing of fuel and oxidizer in this setting turned out to be inappropriate. One of the goals of this work is to repeat the experiments in a flat-radial chamber and carry out detailed measurements of this mode.

\section{THE BASIC RESULTS}

In given paper the schema of circle channel of inner radius $R_{1}$ and outer radius $R_{2}$ with radial injection of mixture from the centre to periphery was used for mixture burning by the waves, rotated axially along the channel. The idealized schema of such propagation for case of anticlockwise rotation is presented on Fig. 6: $\mathrm{AB}$ - rotated $\mathrm{DW}, \mathrm{BC}$ - rotated waves in reaction products (similar to the tail in spinning configuration), 1 - inleakage mixture, 2 - reaction products. Some important aspects of rotated DW were analyzed in this report: the velocities and pressure profiles of rotating waves, velocity deficit and energy-release; multifront system of rotated TWs; correlation of rotation velocity of TW with acoustic characteristics of reaction products; streak-records trajectory of rotated TW on moving film. The high velocity camera for streak-record registration of self-luminosity of rotating waves was used in experiments. The silphon gauge was used for measurement of static pressured in moved injected mixture. The special piezoelectric gauges with thermal shield were constructed for measurement of dynamic pressure profiles in rotating waves, at long duration (up to 5 seconds) of influence of hot products. The microthermocouple was used for measurement of average temperature in different points of combustion chamber.

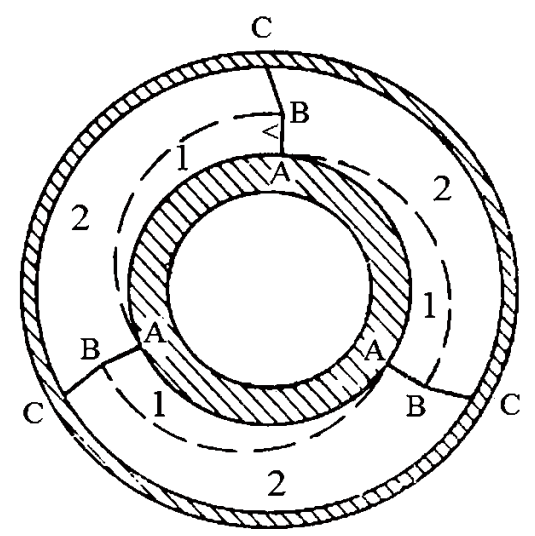

Fig. 6. Idealized schema of 3-heads rotated quasi-detonation in circular combustion channel.

The existence domain of the observed regimes of wave propagation is presented on Fig. 7: 1 - the lower limit for rotated waves (upper boundary for subsonic flames), 2 - the regimes of rotated DW with unsteady transition from one mode to another and short steady behavior, 3 - the regimes of 
rotated DW with high steady propagation during a long time, 4 - the upper limit of regimes of rotated DW (at this the reaction front not propagates along channel and penetrates into central mixture injector, another words it is explosion).

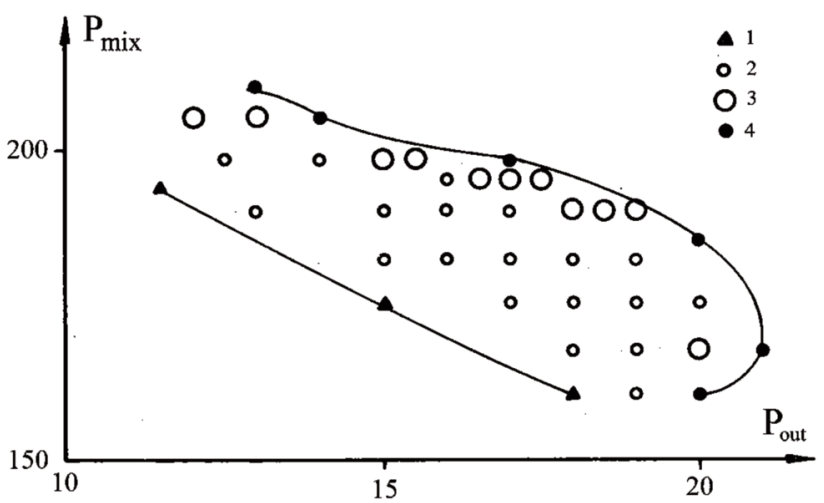

Fig. 7. Some domain of existence of rotating low velocity waves.

At propagation of a single rotated DW along curvilinear channel the trajectory of her luminosity front on moving film seems as cycloid of revolution. At increase of rotated fronts the number of cycloids also increase and its images on film are shifted ones another. At equal distances among individual rotated waves the cycloids on film seems as regular print. When the individual rotated waves are uncoordinated, then on film the chaotic print is observed.

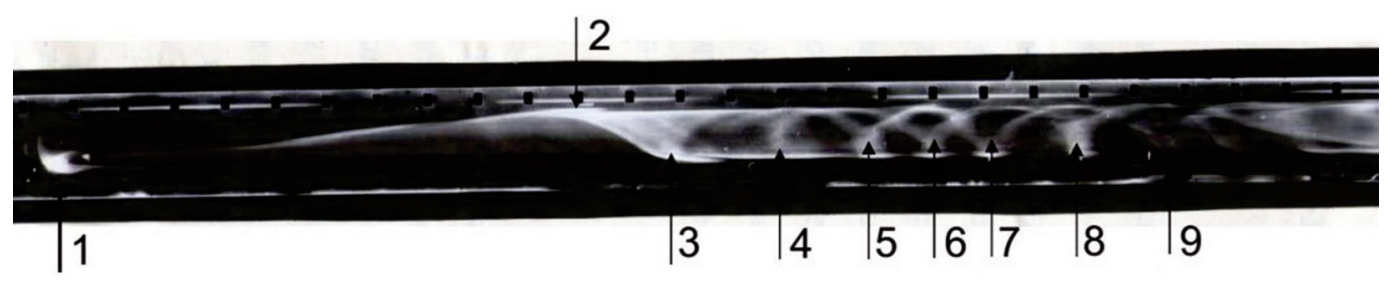

Fig. 8. The initial stage of formation of rotating waves: the trajectories of luminosity zones at their propagation along combustion channel at their registration on moving film.

On Fig. 8 the process of initiation and initial stage of formation of rotating TWs is illustrated as streak-record of circular combustion channel on moving film: 1 - moment of initiation of mixture with the help of high-voltage discharge; 1-2 - propagation of subsonic combustion wave along curvilinear channel; 2-3 - transition from combustion mode to "quasidetonation"; 3-9-trajectories of rotated waves in this very short initial period (about $5 \mathrm{msec}$ ) of total period of existing of rotated waves (about $1 \mathrm{sec}$ ). After 9 the next process of formation of rotated waves was observed. It can be seen on Fig. 8 that during initial stage the single (point 3) or two (point 4) rotated waves try to form in channel, at this both wave propagates in similar direction. On given streak-record the system of single and doubled head rotated waves was found unstable and the imprint of cycloid trajectories on film not obtain the regular picture. It must be emphasized especially, that at spinning regime only single transverse wave of spinning configuration rotates clockwise or anticlockwise. In configuration with two transverse waves in nearspinning regime these waves propagate only in opposite direction and never follow one by one, in contradiction with synchronic propagation of waves in known scheme of rotated detonation engine (RDE). The synchronic propagation of rotated waves with 2, 3 and 4 transverse waves on length of 
circular combustion channel is illustrated on the photos of Fig. 9 - for another (not initial) period of process. From such photo it is easy to estimate the number of rotated waves on the channel length and then calculate the wave velocity with the help of additional data about the rotation period of individual wave (on base of duration of individual cycloid). Additional interpretation of cycloid trajectories of regimes of multiheaded rotated waves is presented on Fig. 9 for number of individual waves $n=2, n=3$ and $n=4$. Please, pay your attention on print for $n=3$ : on upper part of cycloid one can see the inclined line among the neighboring images of rotated waves, which is the boundary among the cold initial mixture and hot reaction products, with inclination angle $\beta$. Because $\beta=\Delta R \cdot n / 2 \pi R \approx u / D_{n}$, then $u \approx D_{n} \cdot \tan \cdot \beta$ : here $u$ - radial velocity of initial mixture across the channel, $D_{n}$ - the velocity of rotated wave. At $n=1 \Delta R=R_{2}-R_{1}$, so $\tan \cdot \beta=1 / \pi \cdot\left(R_{2}-R_{1}\right) /\left(R_{2}+R_{1}\right) \approx 0.046$, so $u \approx 0.046 \mathrm{D}_{1} \approx 110 \mathrm{~m} / \mathrm{s}$ and subsonic regime of mixture outflow. For $n>1$ the value of $u<110 \mathrm{~m} / \mathrm{s}$.

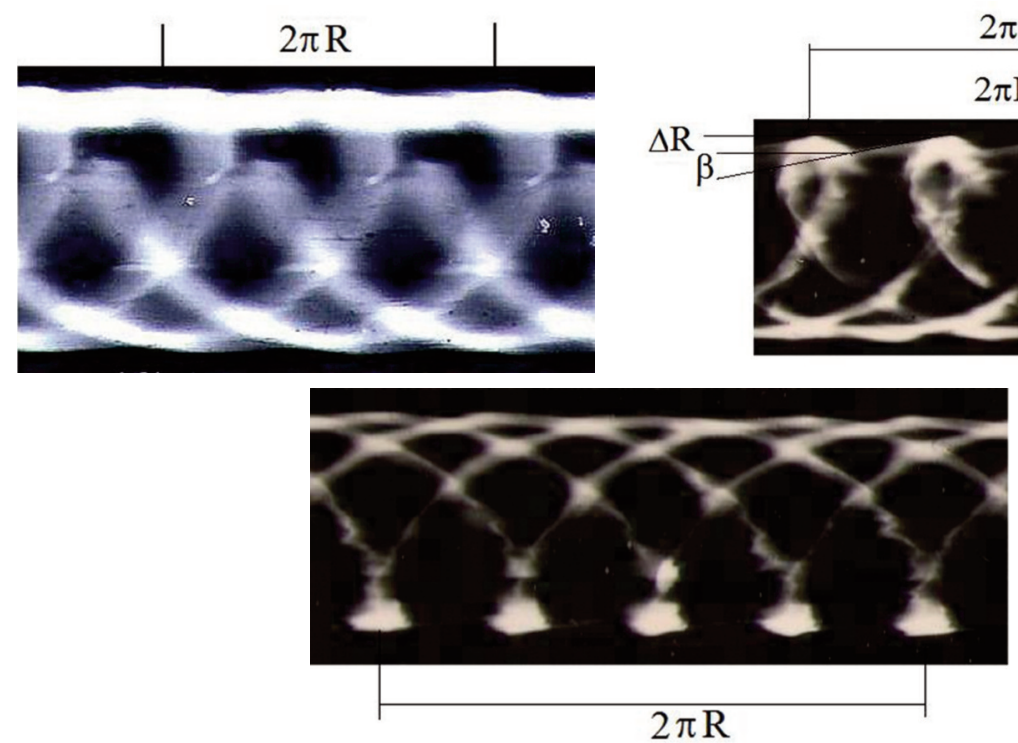

Fig. 9. The trajectories of rotated waves at quasi-steady regimes with 2, 3 and 4 TWs on total length of combustion channel.

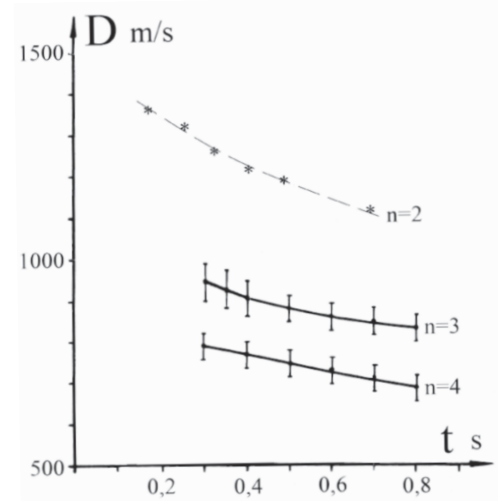

Fig. 10. Experimental velocities of rotated waves on time for different number of DW heads. 
Experimental values of velocity of rotated waves are equal $D_{2} \approx 1300 \mathrm{~m} / \mathrm{s}, D_{3} \approx 900 \mathrm{~m} / \mathrm{s}$ and $D_{4} \approx 800$ $\mathrm{m} / \mathrm{s}$ (Fig. 10), these values are lower the ideal velocity of Chapman-Jouguet DW - about $2300 \mathrm{~m} / \mathrm{s}$ - and are neighbour to the sound speed in products $-1200-1300 \mathrm{~m} / \mathrm{s}$. Such correlation among the velocity of rotated wave and acoustic wave in detonation products is not casual and must be take into account at modeling of rotated DW.

The method of full (as on values, as on direction) compensation of velocity of optic image of rotated front and velocity of film are known. The instantaneous picture of luminosity distribution in rotated wave can be registered independently and such photo with triangle profile for each wave is presented on Fig. 11 upper photo). Such similar compensated photo can be seen and on photo of trajectories on Fig. 9 at $n=3$, where the compensation condition is realized on upper boundary of this imprint. The line with inclination angle $\beta$ on Fig. 9 corresponds to trajectory of boundary among initial mixture and products of its reaction and allow estimate the velocity of mixture outflow (see above).

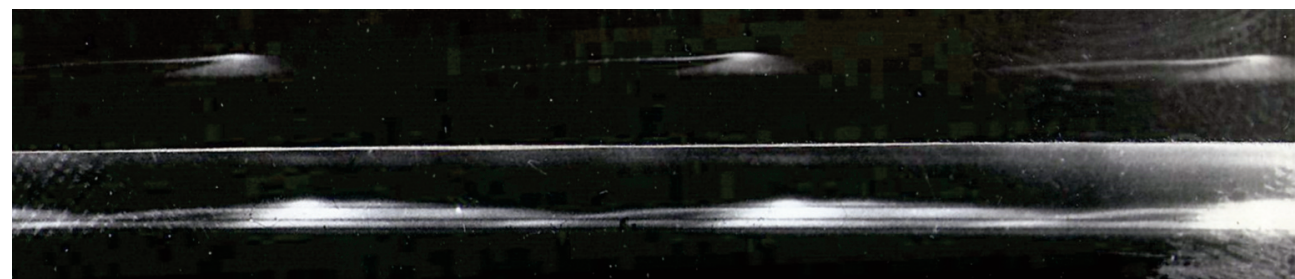

Fig. 11. The photo of self luminosity of rotating waves (the regime of compensated velocity of images of rotated waves and film velocity of streak camera) - upper photo, and similar photo with parallel lines which indicate the location of piezoelectric gauges on radius of combustion channel- lower photo.

It must be emphasized especially, that the size of triangle bright domain of rotated wave is lower the channel width, so at measurement of pressure and temperature in different points of channel width the position of gauges must be identified carefully relative to the rotated wave. Such markers are visible on lower photo on Fig. 11 relatively the luminosity domain.

The typical oscilloscope traces of pressure profiles in different points of rotating waves are presented on Fig. 12. One can see the high stability and periodicity of rotated quasi-detonation waves during the registration period. The greater part of pressure traces have not the form, typical for shock wave with abrupt front, but have the smooth form indicated on acoustic character of influence of hot reaction products on velocity of rotating waves (left photos). Only the rare oscilloscope traces with sharp front were detected by piezoelectric gauge, located near the bright peak of triangle reaction zone of luminosity of rotating wave as on Fig 11. The acoustic character of waves in zone of reaction products and typical for compression wave behavior on leading front of rotated wave may be the main cause that up to now the shock-waves structure of rotated quasi-detonation is not determined.

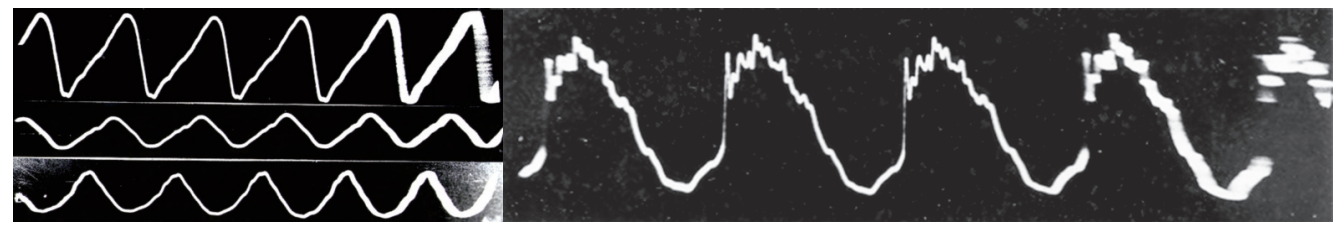

Fig. 12. The typical oscilloscope traces in rotated wave similar to acoustic wave (left) and similar to shock wave (right).

The distribution of maximal values of pressure increase and temperature in different points of channel radius is presented on Fig.13. One can see a correlation about measurement parameters. 

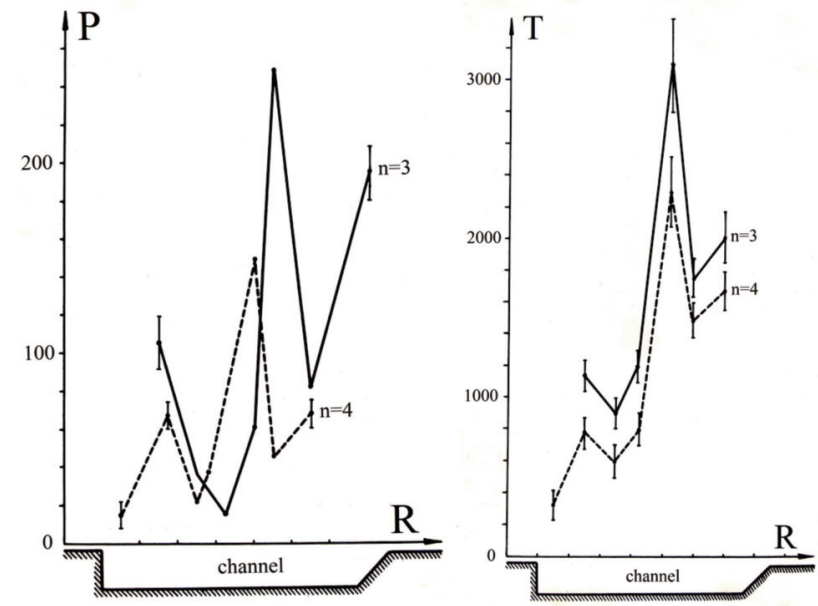

Fig. 13. The plots of maximal amplitude of pressure record in rotated waves and maximal average temperature in different points of combustion channel (on radius).

It must be emphasized again, that in classical theory the value of energy-release $\mathrm{Q}$ at chemical reaction are the same as for supersonic detonation regime, as for subsonic combustion process, but at this the velocity of steady regimes (determined by tangency of MR lines with the Hugoniot curve) differ on 3-4 orders. The Q-values are widely used for estimation of detonation velocity, but practically not used for estimation of burning velocity. Because the regimes with low velocities are typical for heterogeneous medium with great looses (for example, for porous medium), so the interpretation of low velocity in gaseous mixture by insufficient energy release seems not enough valid. The new system for mass, momentum and energy with possible looses of momentum and energy must be analyzed in such case (and for rotated waves) instead of the ideal system without looses. At this, the new definition of prototypes of shock adiabat, MR line and Hugoniot curve is required.

\section{CONCLUSION}

The history of investigations of rotated waves was presented, especially for young researchers. New experimental results about rotated wave were presented: often the rotated waves propagate with supersonic velocity, which is lower in compare with the velocity of ideal detonation wave. Such deviation usually was explained by energy losses outside, what is equivalent to the incomplete energy release of mixture. Because any engine must be operated effectively at extensive variation of parameters, so the low-velocity regime of wave propagation in detonation regimes of mixture burning must be investigated carefully, especially for RDE. Not only the insufficient energy release of mixture and high level of energy losses must be taken into account at numerical modeling of low velocity rotated wave, but also the connection of the wave front with the acoustic vibration of the products. It is hope, that at this the numerous calculated results about rotated quasi-detonation waves will be correlated better with experimental data.

\section{ACKNOWLEDGEMENT}

The problems of detonation waves are included in the State Programme of Fundamental Investigations of Russian Federation. The investigations of such problems in Lavrentyev Institute of Hydrodynamics are supported by the Government Department on Science and Education (GDSE): LIH project III.22.2.1 and Grant of GDSE on Agreement No. 075-15-2020-806 (Contract No. 13.1902.21.0014). 


\section{REFERENCES}

[1] Mallard, E., Le Chatelier, H., 1881, "Sur la vitesse de propagation de l'inflammation dans les mélanges gazeux explosives," Comptes-Rendus Academie des Sciences, Paris, France, 93, pp. 145-148.

[2] Berthelot, M. and Vieille, P., 1883, Ann. Chim. Phys., 5eme Ser, 28, pp. 289.

[3] Michelson, V.A., 1893, "About normal velocity of ignition of combustible gaseous mixture (in Russian),» Uchenie zapiski Imperatorskogo Moskovskogo Universiteta, otdel fizikomatematicheskii, vipusk 10, Moskva, Universitetskaya tipografiya.

[4] Chapman, D. L., 1899, "VI. On the rate of explosion in gases,", The London, Edinburgh, and Dublin Philosophical Magazine and Journal of Science, 47(284), pp. 90-104.

[5] Jouguet, E., 1913, "Sur l'onde explosive,» CR Acad. Sci., Paris, 156, pp. 872-875.

[6] Campbell, C., Woodhead, D.W., 1927, "Striated photographic records of explosion waves," Journal of Chemical Soc., pp. 1572-1578.

[7] Manson, N., 1947, "Propagation des detonations et des deflagrations dans les mélanges gazeux," Dr. Sc. Thesis, University of Paris, ONERA and IFP, Paris.

[8] Voinov, A.N., 1950, "On the mechanism of formation of the spinning detonation (in Russian)," Doklady of the Academy of Sciences, USSR, 73, pp. 125-128.

[9] Voitsekhovsky, B.V., 1957, "On spinning detonation (in Russian)," Dokladi of the Academy of Sciences, USSR, 114, pp. 717-720.

[10] Voitsekhovsky, B.V., 1959, "Steady detonation (in Russian)," Dokladi of the Academy of Sciences, USSR, 129(6), pp. 1254-1259.

[11] Voitsekhovsky, B.V., Mitrofanov, V.V., Topchian, M.E., 1963, "Structure of the detonation front in gases (in Russian),” Izdatielstvo SB AN USSR, Novosibirsk.

[12] Zeldovich, Y.B., 1940, Zh. Exp. Teor. Fiz., 10(5), pp. 542-568. Also: English translation, NACA TN No. 1261 (1950).

[13] Bykovskii, F.A., Vasil'ev, A.A., Vedernikov, E.F., Mitrofanov, V.V., 1994, "Detonation burning of gas mixture in radial circled channels, "Combustion, Explosions\&Shock Waves, 30(4), pp. 111-118.

[14] Bykovskii, F.A., Zhdan, S.A., Vedernikov, E.F., 2006, ”Continuous Spin Detonations”, Journal of Propulsion and Power, 22(6), pp. 1204-1216. 10.2514/1.17656

[15] Bykovskii, F.A., Zhdan, S.A., 2013, “Continuous spinning detonation (on Russian),” Novosibirsk, izdatelstvo SB RAS, 423 pages.

[16] Wolanski, P., Kindracki, J., and Fujiwara, T., 2006, "An experimental study of small rotating detonation engine," "Pulse and continuous detonation" (Edited by G. Roy, S. Frolov, J. Sinibaldi), M., Torus Press, pp. 332-338.

[17] Hishida, M., Fujiwara, T., Wolanski, P., 2009, "Fundamental of rotating detonation”, Shock Waves, 19(1), pp. 1-10. 10.1007/s00193-008-0178-2.

[18] Fujiwara, T., Hishida, M., Kindracki, J., Wolanski, P., 2009, "Stabilization of detonation for any incoming mach numbers," Combust Explos Shock Waves, 45, pp. 603-5. 10.1007/s10573-0090072-y.

[19] Wolański, P., 2011, "Rotating detonation wave stability," Proceedings of the 23rd International Colloquium on the Dynamics of Explosions and Reactive Systems. Irvine, California, USA.

[20] Kindracki, J., Kobiera, A., Wolański, P., Gut, Z., Folusiak, M., Swiderski, K., 2011, "Experimental and numerical study of the rotating detonation engine in hydrogen-air mixtures," Prog. Propul. Phys., 2, pp. 555.

[21] Wolanski, P., 2013, “Detonative propulsion,” Proc Combust Inst., 34, pp. 125-58. $10.1016 /$ j.proci.2012.10.005.

[22] Wolanski, P., 2015, “Application of the continuous rotating detonation to gas turbine," Appl Mech Mater., 782, pp. 3-12. 10.4028/www.scientific.net/AMM.782.3. 
[23] Tsuboi, N., Hayashi, A.K., 2006, "Numerical simulation of continuous spinning detonation in a circular tube," In: "Pulsed and Continuous Detonations", (Edited by G.Roy, S.Frolov, J.Sinibaldi), Torus Press Ltd., Moscow, pp. 186-192.

[24] Virot, F., Khasainov, B., Desbordes, D., and Presles, H.-N., 2007, "Spinning Detonation: Experiments and Simulations," Proceedings 21st ICDERS, Poitiers, France.

[25] Levin, V.A., Manuylovich, I.S., Markov, V.V., 2015, "Formation of spin detonation in channels of circular cross section,” DokladyPhys., 60(2), pp. 85-88. 10.1134/S1028335815020093.

[26] Levin, V.A., Manuylovich, I.S., Markov, V.V., 2017, "Cellular and spin detonation in 3D channels," 30th International Symp. on Shock Waves, 1, Springer Intern. Publishing., pp. 447-452. 10.1007/978-3319-46213-4_76.

[27] Davidenko, D.M., Gokalp, I., Kudryabtsev, A.N., 2008, "Numerical study of the continuous detonation wave rocket engine," AIAA 2008-2680, pp. 1-8.

[28] Shao, Y.T., Liu, M., Wang, J.P., Fujiwara, T., 2009, "Numerical investigation of continuous detonation engine," Proceeding Intern. 22 $2^{\text {nd }}$ ICDERS, Minsk, Belarus, CD ROM, No. 12.

[29] Schwer, D., Kailasanath, K., 2011, "Numerical investigation of the physics of rotating detonationengines,” Proc Combust Inst., 33, pp. 2195-202. 10.1016/j.proci.2010.07.050.

[30] Nakayama, H., Moriya. T., Kasahara, J., Matsuo, A., Sasamoto, Y., Funaki, I., 2012, "Stable detonation wave propagation in rectangular-cross-section curved channels," Combust. Flame, 159, pp. 859-869. 10.1016/j.combustflame.2011.07.022.

[31] Vasil'ev, A.A., 2013, "The principal aspects of application of detonation in propulsion systems," Journal of Combustion, 2013, Article ID 945161. 10.1155/2013/94516.

[32] Frolov, S.M., Dubrovskii, A.V., Ivanov, V.S., 2013, "Three-dimensional numerical simulation of operation process in rotating detonation engine," Prog Propuls Phys., 4, pp. 467-88. 10.1051/eucass/201304467.

[33] Anand, V., and Gutmark, E., 2019, "Rotating detonation combustors and their similarities to rocket instabilities," Progress in Energy and Combustion Science, 73, pp. 182-234.

\section{WIRUJĄCA DETONACJA: HISTORIA, WYNIKI, PROBLEMY}

\section{Abstrakt}

Wśród współczesnych prac poświęconych numerycznemu modelowaniu fal rotacyjnych większość prac opiera się na założeniu, że fala ta rozchodzi się z prędkością równą prędkości idealnego modelu detonacji z czołem płaskim Chapmana-Jougueta. Ale eksperymentalne prędkości wirujących fal detonacyjnych z reguły są mniejsze (a nawet znacznie mniejsze) od prędkości idealnej detonacji Chapmana-Jougueta. Takie działania nazywane są detonacją z małą prędkością lub quasi-detonacją, a ich charakterystyka nie jest dokładnie zbadana. Ponadto, podobnie jak w przypadku wirującej detonacji, zaobserwowano silny związek prędkości fal poprzecznych z falami akustycznymi produktów reakcji. Tak więc nowy model z uwzględnieniem strat impulsu i energii musi być zastosowany do modelowania numerycznego RDE i należy przeprowadzić nowe badania eksperymentalne o zaniżonej prędkości. W artykule przeanalizowano kilka ważnych aspektów wirujących fal detonacyjnych oraz nowe wyniki eksperymentalne: wieloczłonowy układ fal rotacyjnych; korelacja prędkości rotacji fal z charakterystyką akustyczną produktów reakcji; smuga rejestrująca trajektorię fal wirujących na poruszającej się kliszy; profile ciśnienia i temperatury fal wirujących; deficyt prędkości i uwolnienie energii.

Słowa kluczowe: wirująca detonacja, obrócona fala detonacyjna, detonacja przy niskiej prędkości, „quasi-detonacja”, wyzwolenie energii w mieszaninach reaktywnych, niestabilność strefy reakcji, powiązanie niestabilności DW z wibracjami akustycznymi produktów reakcji, utrata impulsu energii. 